\title{
Corrigendum to: Anecdotic observations of homosexual behaviour among male capuchin monkeys (Sapajus sp.) (Behaviour 158/1 (2021) 89-97, DOI: 10.1163/1568539X-bja10055)
}

\author{
Henrique P. Rufo* and Eduardo B. Ottoni \\ Instituto de Psicologia, Universidade de São Paulo, Avenida Professor Mello de Morais, \\ 1721 Butantã, São Paulo, SP 05508-0, Brazil \\ *Corresponding author's e-mail address: henrique.rufo@gmail.com
}

Received 31 August 2020; initial decision 22 September 2020; revised 3 December 2020; accepted 4 December 2020; published online 23 February 2021

In the above-mentioned article, the sentence on page 95, line 3 reading:

We can also speculate that at least two of these four events may be related with getting access to the experimental apparatus: in events $\mathrm{C}$ and $\mathrm{D}$, one adult male was standing on and interacting with the box when a juvenile male approached.

should read:

We can also speculate that at least two of these four events may be related with getting access to the experimental apparatus: in events $\mathrm{C}$ and $\mathrm{D}$, one male was standing on and interacting with the box when another one approached.

The authors apologise for any confusion caused. 